\title{
Intimate Relationships Affected by Breast Cancer: Interventions for Couples
}

\author{
Tanja Zimmermann \\ Clinic for Psychosomatics and Psychotherapy, Hanover Medical School, Hanover, Germany
}

Keywords

Breast cancer - Psychosocial intervention . Couple-based interventions

\section{Summary}

A cancer diagnosis imposes significant emotional distress on a substantial proportion of patients and their partners, posing many challenges for both members of a couple. Facing a breast cancer diagnosis, couples may experience psychosocial distress, which might also affect their individual and dyadic functioning. Coping with cancer from a couple-based perspective as a dyadic stressor can profoundly influence psychosocial adjustment as well as individual and dyadic functioning of patients and spouses. Dyadic coping allows a better matching of needs, sharing of worries, and mutual support, resulting in higher relationship satisfaction. The aim of this article is to provide an overview of the issues faced by women diagnosed with breast cancer and their spouses, with particular emphasis on interventions for couples coping with cancer. The effectiveness of couplebased interventions is summarized with a critical discussion. For further research, a better understanding of the challenges couples coping with cancer may face and more insights on how to improve interventions for couples might facilitate improvements in the quality of cancer care.

\section{Introduction}

Breast cancer is the most common cancer in women worldwide. Globally, it is also the principal cause of death from cancer among women. 1 in 8 women will develop breast cancer in their lifetime [1]. While only a few decades ago the majority of women did not survive breast cancer, advances in medicine and diagnostics and the higher aging of the population have led to an increased number of persons diagnosed with breast cancer as well as to increased survival rates. In Western countries, $89 \%$ of women diagnosed with breast cancer are still alive 5 years after their diagnosis. Therefore, breast cancer survivors are the largest group of cancer survivors [2]. Cancer is increasingly viewed and treated as a chronic disease, due to advances in treatment efficacy and improvements in survival rates. Still, despite the growing number of people treated or followed up for cancer or having survived the disease, a cancer diagnosis remains a life-threatening disease that can affect psychosocial functioning even years after the medical treatment has ended. Cancer patients can experience psychosocial, emotional, and physical distress [3].

There is a growing awareness that a cancer diagnosis and its treatment not only influence the patients but also their families, friends and caregivers [4]. Usually, the primary caregiver of the woman is her spouse. In addition, cancer patients identify their partners as their most important source of support [5]. Thus, due to more women surviving longer and being in a committed relationship at the time of diagnosis, an ongoing challenge is how to cope with the disease, its treatment, and its long-term sequel within the context of their relationships. Breast cancer introduces individual and relationship challenges for both the patient and her partner [6]. Research has shown that some of these issues can serve to bring a couple closer together (cohesion) while others can disrupt relationship functioning in different ways (e.g., by communication problems, less intimacy, and decreased relationship satisfac-

\section{KARGER \\ Fax +497614520714

\section{(๑) 2015 S. Karger GmbH, Freiburg}

$1661-3791 / 15 / 0102-0102 \$ 39.50 / 0$
Prof. Dr. Tanja Zimmermann

Clinic for Psychosomatics and Psychotherapy Hanover Medical School

Carl-Neuberg-Str. 1, 30625 Hanover, Germany

Zimmermann.Tanja@mh-hannover.de 
tion) at different stages of the disease-recovery timeline. Therefore, the disease can affect both members of the dyad and can induce serious distress and negatively influence successful coping throughout the cancer journey [6].

\section{Impact on Individual and Dyadic Functioning}

Both members of the dyad can experience fear, uncertainty, depression, and anxiety. In women with early-stage breast cancer, $7-46 \%$ and $32-45 \%$ show clinically significant levels of depression and anxiety, respectively $[7,8]$. The prevalence rates of depression and anxiety among spouses of cancer patients are in the range of $10-53 \%$ and $16-56 \%$, respectively [9]. The partner has to adjust to the woman's disease, has his own worries, and is confronted with the potential loss of his wife; he is burdened by taking on the partner's tasks and by providing support and caring. Partners often experience a 'double role': On the one side, they may suffer from their own psychological distress, and on the other side, they are the main source of support for the distressed women [10]. The diagnosis and medical treatment of breast cancer also lead to additional problems with regard to body image, sexual functioning, and intimate relationships.

\section{Body Image and Sexuality}

Women with breast cancer have to cope with significant changes in body appearance (e.g., scarring, hair loss, disfigurement) and functioning (e.g., numbness, pain). Breast cancer and its physical side effects can profoundly affect a woman's body image and can contribute to lower self-esteem, less desire for sexual activity, lower libido, and depression [11]. A negative body image has strong implications for psychosocial adjustment and social functioning. In women with breast cancer, the iatrogenic menopause can cause significant detriment to sexuality by, e.g., a lowered libido, decreased vaginal lubrication and dyspareunia, as well as numbness in previously sensitive breasts [12]. In addition, psychosocial aspects such as depression or anxiety can contribute to sexual disturbances. Sexual problems are frequent in cancer survivors [2] and can negatively affect the relationship satisfaction [13]. Otherwise, for women with breast cancer, the relationship quality has emerged as a strong predictor of sexual functioning [14]. Therefore, sexual functioning and the enhancement or preservation of relationship satisfaction should be addressed in interventions for couples coping with cancer.

\section{Dyadic Stress and Coping}

Emotional and instrumental social support from partners appear to be important contributors to the women's adjustment to breast cancer and thus to their quality of life after the diagnosis. Despite this need for support, a cancer diagnosis nevertheless frequently leads to maladaptive patterns of interaction between the patient and her partner that negatively influence the couple's relationship functioning. They must cope with distress induced by the physical side effects and a potentially increased functional disability associated with cancer and its treatment, and also with role changes in their relationship. Furthermore, the patient and her partner can experience important restrictions in their social life in addition to interruptions of their daily life. Economic or financial consequences, household and child care responsibilities, and the insecure future are further stresses and strains [15]. A challenge for couples could also be to cope with changes in established communication patterns, responsibilities, or roles [16]. Thus, for some couples, the cancer experience can lead to significant adjustment and relationship difficulties, which may result in feelings of greater conflict and less intimacy. Despite the negative consequences of a cancer diagnosis, a growing amount of literature also reports positive aspects of the cancer experience, such as greater appreciation of life, changed priorities, closer relationships, and enhanced spirituality [17-19].

For a long time, cancer was considered as an individual stress experience demanding individual coping strategies. However, both members of the dyad and the couple's functioning can be profoundly affected by the cancer experience, with interrelations between the psychological distress states of patients and partners [20]. For most of the women with breast cancer, the men are the main source of instrumental and emotional support during a time when the men themselves could be under extreme stress. Both partners of the dyad interact with and mutually influence each other. There is some evidence emerging that dyadic processes, specifically communication and dyadic coping, may be involved in the adjustment process for both partners [21]. Consequently, it is obvious to consider the individual and dyadic coping of the patient in relation to the individual psychological distress, and vice versa. Therefore, cancer can be a stressor concerning both partners simultaneously, and coping with cancer should be viewed as a dyadic affair [20, 22].

There is growing evidence that dyadic processes as dyadic coping and communication may influence the adjustment to cancer for both partners. Couples may tend to be kind to each other under the stressful influence of the cancer diagnosis, which may result, e.g., in increased positivity in the relationship. However, this may occur within the context of avoidance (e.g., not talking about cancer and disease-related stressors, mutual withdrawal, hiding concerns, denying worries, and not upsetting the other or hostility due to the stressors associated with the disease). Thus, despite what might appear to be an increase in explicit positive interaction between partners, underlying negative behaviors can be deleterious to couple functioning and may jeopardize the long-term adjustment to the cancer. This phenomenon is known as 'protective buffering' and shows strong associations with higher levels of patient and partner distress [23]. Therefore, dyadic coping as a stress management strategy supports couples in being mutually involved in the stress coping process by providing and receiving support from each other and engaging in joint problem-solving as well as shared emotion regulation, to act as a team rather than as individuals [21, 
24]. Psychosocial interventions should include both partners of the couple and should be aimed at supporting and strengthening the coping abilities of both partners.

\section{Interventions for Couples}

Given that coping with cancer should be characterized as a dyadic affair, a growing amount of literature involving couple-based interventions came up over the past 2 decades. Nevertheless, the majority of these studies were published only in the last decade. The most promising results in enhancing the well-being of both partners are shown by interventions with multiple targets (e.g., improvements in communication and sexuality, reduction of emotional distress, strategies to enable partners to express their distress [25], and stress communication (e.g., expressing worries, needs, and feelings regarding cancer- or relationship-related topics), supportive behavior, and effective dyadic coping [15]). Intimacy emerged as a key component of relationship quality and could serve as a buffer for psychological distress [26].

Women with cancer who are in committed relationships express a great need for support from their partners, even more than from others [27]. Although partners show high motivation to offer this support, they may have difficulties in providing social support because of their own distress or because they do not know how to be the type of support person the woman needs. In addition, the needs of the patient change across time, making support even more complicated. Hence, many women feel disappointed by their interactions with their partners when addressing cancer. This dissatisfaction can occur even within the context of an overall high relationship satisfaction. The challenges are likely to persist beyond the completion of treatment, but are most salient during the treatment phase, due to the acute burden of the diagnosis and treatment these couples have to confront.

\section{Components of Couple Interventions}

The content of interventions for couples coping with cancer is heterogeneous. A combination of skill training and psycho-educational intervention is recommended [28]. The components can be discussed according to the development-contextual model of couples coping with chronic illness [29] in 3 dimensions: dyadic appraisal, dyadic coping, and dyadic adjustment. Dyadic appraisal was conceptualized at the individual and dyadic levels and contains the appraisal of disease, self-efficacy, and communication [28]. How do both partners perceive and understand their coping abilities and their emotional state? How do they appraise the disease as a unit? In this process, the quality of communication influences the couple's appraisal of their disease and efficacy [28]. Dyadic coping supports couples in coping with the disease as a team [15]. Enhancing communication skills, self-efficacy, and dyadic coping should influence the dyadic adjustment measured in quality of life and mental, physical, and relationship satisfaction [30]. Dyadic coping may reduce stress but, even more importantly, may increase intimacy, cohesion, and mutual confidence [24].
Thus, given the challenges that breast cancer poses for the couple's relationship, in addition to the central importance of the couple's relationship to the patient's and partner's adjustment, it is critical to determine the most efficacious way to assist couples in facing a breast cancer diagnosis. There is increasing recognition that the quality of marital interactions, rather than global social support, the mere presence of a partner, or even overall marital satisfaction, is essential to achieve positive patient outcomes. Patientpartner interaction patterns that have been associated with positive patient adaptation include candid communication about cancerrelated issues, the ability to express emotions to a partner who is able to listen supportively, and effective problem-solving skills. For instance, in patients with breast cancer, high levels of empathy from spouses were a stronger predictor of patient psychological adjustment than overall marital satisfaction [31]. In addition, the ability to express emotions and to communicate openly with partners about cancer has been associated with fewer emotional and physical complaints and higher levels of self-esteem and perceived control [32], in addition to higher relationship satisfaction [33, 34]. Conversely, negative or unhelpful interaction patterns, such as partner avoidance and criticism, hiding concerns from each other, mutual denying of worries, and avoidance of shared discussion, are associated with poorer patient adjustment, including increased distress, maladaptive coping strategies, and intrusive thoughts about the illness [15] along with lower relationship functioning [21]. A recent review illustrates the importance of stress communication, supportive behavior and effective dyadic coping for relationship satisfaction in couples coping with cancer [15]. In addition, the scope of communication should be enlarged from cancer-related issues to the couple's life in general [34]. Helping couples to maintain relationship normalcy and quality during the cancer trajectory and to cope as a unit may lead to better communication and enhanced relationship intimacy [26].

An often neglected subject of couple-based interventions is the caregivers' self-care [28]. Partners often put their own needs on hold, resulting in less time spent on maintaining their own mental, social and physical health [35]. This behavior could affect the partners' own health.

\section{Effectiveness of Interventions for Couples}

The benefit of psychosocial interventions for couples coping with cancer still remains unclear. Some reviews and meta-analyses report that these interventions are effective in improving individual and dyadic functioning and have beneficial effects on relationship quality and psychosocial adjustment, albeit with small to medium effect sizes [19, 36, 37]; others show heterogeneous evidence [38]. An often expressed critique is that the studies have only small sample sizes and are therefore underpowered to examine changes in the multiple outcomes measured, which results in only small to medium effect sizes [39]. For example, in a recent meta-analysis [19] with 20 randomized controlled trials, 9 studies included in the meta-analysis had 35 or less couples per group. One reason for the small sample size could be the challenging recruitment process. Badr and Krebs [19] reported refusal rates ranging from 3 to $82 \%$. 
Table 1. Recommendations regarding intervention components for couples coping with cancer

\begin{tabular}{|c|c|c|}
\hline Component & Description & Goal \\
\hline \multicolumn{3}{|l|}{ Intervention techniques } \\
\hline $\begin{array}{l}\text { Communication and } \\
\text { problem-solving } \\
\text { skills }\end{array}$ & $\begin{array}{l}\text { open communication and expression of worries (e.g., fear } \\
\text { of disease progression or recurrence), emotions, and needs } \\
\text { regarding cancer-related and relationship-related topics; } \\
\text { open communication with children; supportive listening, } \\
\text { self-disclosure and empathy; "relationship talk" }\end{array}$ & $\begin{array}{l}\text { improvement of coping and adjustment to cancer; } \\
\text { enhancement of relationship satisfaction; reduced } \\
\text { psychological distress }[15,32,34]\end{array}$ \\
\hline Dyadic coping & $\begin{array}{l}\text { both partners are mutually involved in the stress coping } \\
\text { process: receiving and providing support from each other } \\
\text { with joint problem-solving and shared emotion regulation } \\
{[24]}\end{array}$ & $\begin{array}{l}\text { enhancement in coping with cancer and relationship } \\
\text { functioning [15] }\end{array}$ \\
\hline Supportive behavior & $\begin{array}{l}\text { thoughtful, respectful and appreciative attitude toward } \\
\text { the patient/partner; approving the other's self-efficacy, } \\
\text { resources, and strengths }\end{array}$ & $\begin{array}{l}\text { enhancement of relationship satisfaction [15]; better } \\
\text { integration of cancer into life }[29,31]\end{array}$ \\
\hline Psycho-education & $\begin{array}{l}\text { providing information on the diagnosis, medical treatment } \\
\text { and its side effects as well as on how to manage the } \\
\text { challenges together as a couple; symptom management }\end{array}$ & reduction of depression and anxiety [37] \\
\hline \multicolumn{3}{|c|}{ Intervention topics that should be addressed } \\
\hline Caregivers' self-care & consideration of the caregiver's burden and needs & $\begin{array}{l}\text { benefit for the caregiver's physical, mental and social } \\
\text { health and also for the patient and the couple; } \\
\text { enhancement/improvement of coping behavior, } \\
\text { self-efficacy, and quality of life }[9,35]\end{array}$ \\
\hline $\begin{array}{l}\text { Body image/ sexual } \\
\text { functioning / intimacy }\end{array}$ & $\begin{array}{l}\text { addressing topics related to changes in body appearance } \\
\text { and functioning and its impact on sexual functioning; } \\
\text { sensate focus and communication about sexual problems; } \\
\text { incorporating the cancer into the relationship to sustain } \\
\text { normalcy }\end{array}$ & $\begin{array}{l}\text { improvement of the woman's self-image, intimacy, } \\
\text { and perceptions of her partner's view of her body; } \\
\text { enhancement of the couple's well-being, sexual } \\
\text { adjustment, and sexual functioning and satisfaction along } \\
\text { with relationship quality and satisfaction }[25,26,45-47]\end{array}$ \\
\hline Positive aspects & $\begin{array}{l}\text { addressing positive aspects of the disease such as greater } \\
\text { appreciation of life, changed priorities, closer relationship, } \\
\text { and enhanced spirituality }\end{array}$ & enhancement of couple cohesion [17] \\
\hline
\end{tabular}

Indeed, only few studies report a detailed description of the reasons for refusal. Distance from the study center, fear of randomization, and the perceived burden of study participation are documented barriers. Timing or scheduling issues and age (i.e., younger couples are more likely to participate than older ones) emerged as key factors $[19,37]$. More research is required to identify barriers and obstacles for couples to participate in couple-based interventions (e.g., by approaching couples at routine clinic visits, scheduling study-related appointments with medical appointments, decreasing the number of sessions, expanding the delivery methods by conducting trials by phone, the Internet or in the couples' homes, enhancing the cooperation with physicians or clinic staff, and increasing the perception that psychosocial interventions are an important part of overall medical care) $[19,40]$ and to identify the couples' preferences for interventions considering factors such as disease stage, age, feasibility, and cost effectiveness [19].

Another reason for the heterogeneity of evidence could be that only a subgroup of patients with cancer and partners suffers from increased distress [20]. Given that most interventions were offered to all patients regardless of their distress level, floor effects occur [38]. In addition, there is a strong association between baseline and outcome distress [41]. Badr and Krebs [19] suggest the identification of profiles of couples at risk who may benefit from couple-based in- terventions. Moreover, screening for relationship and/or psychological distress can be useful. In a recent meta-analysis, only 19 of 198 retrieved studies preselected patients according to their psychological distress, but these interventions reported large effects [38].

Most studies include couples with newly diagnosed patients with early-stage cancer (patients with poor prognosis are underrepresented) [20] and only short-term follow-up. Therefore, the influence of the length or timing of the intervention on the outcome remains unclear, besides the need of booster sessions to maintain the positive impact of the intervention.

Researchers criticize the variation or absence of theoretical models or frameworks, the variation in the intervention approaches, and the diversity of reported outcomes [19, 28]. The majority of interventions were modified from marital therapy interventions developed for healthy people or couples with relationship problems, or from existing cognitive behavioral therapy (CBT) interventions developed for individuals. Thus, it remains unclear whether this approach is appropriate or whether couple-based intervention may be best applied in different ways, depending on the difficulties and issues encountered by the couple [42]. For example, for a dissatisfied couple, the focus of the intervention could be on the relationship and techniques from couple therapy, whereas in couples who are satisfied with their relationship it may be more 
helpful to focus on the medical and psychosocial challenges of the cancer by providing, e.g., information on the medical treatment and side effects and on how to manage the challenges together.

Other aspects that could influence the efficacy of interventions for couples could be the timing, dosage, and delivery of the intervention and program flexibility. Couples often experience the time immediately after the diagnosis as the most emotionally taxing [43], whereas others emphasize the time when the medical treatment has ended and the transition back to 'normal' life is expected, including reprioritizing life goals and management of healthy lifestyle changes $[31,44]$. Thus, the content of an intervention should vary depending on the couple's needs at different time points during the cancer journey [37]. Li and Loke [28] and Regan et al. [37] recommended an appropriate dosage of sessions (e.g., 6 sessions), delivery by trained professionals (higher effect sizes for professionals with mental health background [19]), and greater variation in the contents and mode of delivery of couple-based interventions. Furthermore, more studies are needed to identify gender differences to tai- lor interventions to the specific wants and needs of women with breast cancer and their partners. Table 1 gives an overview of useful components for couple-based interventions emerging from existing research, which provide flexible modularity.

Nevertheless, the effect sizes for couple-based interventions are comparable to other psycho-oncologic interventions [38] and to those reported in meta-analyses of patient-only and partner-only interventions [37]. In sum, couple-based interventions have promising effects on multiple aspects of psychosocial distress for both the patients and their partners. However, more research is necessary to strengthen future trials methodologically as well as conceptually and to determine ways of integrating couple-based interventions into routine clinical cancer care.

\section{Disclosure Statement}

The author has no conflicts of interest to declare.

\section{References}

1 Tao Z, Shi A, Lu C, Song T, Zhang Z, Zhao J: Breast cancer: epidemiology and etiology. Cell Biochem Biophys 2014, in press

2 Valdivieso M, Kujawa AM, Jones T, Baker LH: Cancer survivors in the United States: a review of the literature and a call to action. Int J Med Sci 2012;9:163-173.

3 Pirl WF, Fann JR, Greer JA, Braun I, Deshields T, Fulcher C, Harvey E, Holland J, Kennedy V, Lazenby M, Wagner L, Underhill M, Walker DK, Zabora J, Zebrack B, Bardwell WA: Recommendations for the implementation of distress screening programs in cancer centers: report from the American Psychosocial Oncology Society (APOS), Association of Oncology Social Work (AOSW), and Oncology Nursing Society (ONS) joint task force. Cancer 2014;120:2946-2954.

4 Girgis A, Lambert SD: Caregivers of cancer survivors: the state of the field. Cancer Forum 2009;33:167-171.

5 Pistrang N, Barker C: The partner relationship in psychological response to breast cancer. Soc Sci Med 1995; 40:789-797.

6 McClure KS, Nezu AM, Nezu CM, O’Hea EL, McMahon C: Social problem solving and depression in couples coping with cancer. Psychooncology 2012;21:11-19.

7 Gallagher J, Parle M, Cairns D: Appraisal and psychological distress six months after diagnosis of breast cancer. Br J Health Psychol 2002; 7:365-376.

8 Omne-Ponten M, Holmberg L, Burns T, Adami HO, Bergstrom R: Determinants of the psycho-social outcome after operation for breast cancer. Results of a prospective comparative interview study following mastectomy and breast conservation. Eur J Cancer 1992;28A:1062-1067.

9 Girgis A, Lambert S, Johnson C, Waller A, Currow D: Physical, psychosocial, relationship, and economic burden of caring for people with cancer: a review. J Oncol Pract 2013;9:197-202.

10 Zimmermann T: Cancer: psychosocial aspects; in Wright JD (ed): International Encyclopedia of the Social \& Behavioral Sciences, ed 2. Oxford, Elsevier, 2015.

11 Fobair P, Stewart S, Chang S, D'Onofrio C, Banks P, Bloom J: Body image and sexual problems in young women with breast cancer. Psychooncology 2006;15: 579-594.
2 Morreale MK: The impact of cancer on sexual function. Adv Psychosom Med 2011;31:72-82.

13 Burwell SR, Case LD, Kaelin C, Avis NE: Sexual problems in younger women after breast cancer surgery. J Clin Oncol 2006;24:2815-2821.

14 Gilbert E, Ussher JM, Perz J: Sexuality after breast can cer: a review. Maturitas 2010;66:397-407.

15 Traa MJ, De Vries J, Bodenmann G, Den Oudsten BL: Dyadic coping and relationship functioning in couples coping with cancer: a systematic review. Br J Health Psychol 2015;20:85-114.

16 Manne S, Badr H: Intimacy processes and psychological distress among couples coping with head and neck or lung cancers. Psychooncology 2010;19:941-954.

17 Dorval M, Guay S, Mondor M, Masse B, Falardeau M, Robidoux A, Deschenes L, Maunsell E: Couples who get closer after breast cancer: frequency and predictors in a prospective investigation. J Clin Oncol 2005;23: 3588-3596.

18 Tedeschi RG, Calhoun LG: Posttraumatic growth: conceptual foundations and empirical evidence. Psychol Inq 2004;15:1-18.

19 Badr H, Krebs P: A systematic review and meta-analysis of psychosocial interventions for couples coping with cancer. Psychooncology 2013;22:1688-1704.

20 Hagedoorn M, Sanderman R, Bolks HN, Tuinstra J, Coyne J: Distress in couples coping with cancer: a meta-analysis and critical review of role and gender effects. Psychol Bull 2008;134:1-30.

21 Badr H, Carmack CL, Kashy DA, Cristofanilli M, Revenson TA: Dyadic coping in metastatic breast cancer Health Psychol 2010;29:169-180.

22 Kayser K, Watson LE, Andrade JT: Cancer as a 'wedisease': examining the process of coping from a relational perspective. Fam Syst Health 2007;25:404-418.

23 Manne SL, Norton TR, Ostroff JS, Winkel G, Fox K, Grana G: Protective buffering and psychological distress among couples coping with breast cancer: the moderating role of relationship satisfaction. J Fam Psychol 2007;21:380-388.

24 Bodenmann G: A systematic-transactional view of stress and coping in couples. Swiss J Psychol 1995;54: $34-49$.
25 Wootten AC, Abbott JM, Farrell A, Austin DW, Klein B: Psychosocial interventions to support partners of men with prostate cancer: a systematic and critical review of the literature. J Cancer Surviv 2014;8:472-484.

26 Manne SL, Siegel S, Kashy D, Heckman CJ: Cancerspecific relationship awareness, relationship communication, and intimacy among couples coping with early stage breast cancer. J Soc Pers Relat 2014;31:314-334.

27 Manne S, Ostroff J, Sherman M, Heyman RE, Ross S, Fox K: Couples' support-related communication, psychological distress, and relationship satisfaction among women with early stage breast cancer. J Consult Clin Psychol 2004;72:660-670.

28 Li Q, Loke AY: A systematic review of spousal couplebased intervention studies for couples coping with cancer: direction for the development of interventions. Psychooncology 2014;23:731-739.

29 Berg CA, Upchurch R: A developmental-contextual model of couples coping with chronic illness across the adult life span. Psychol Bull 2007;133:920-954.

30 Larson JS: The conceptualization of health. Med Care Res Rev 1999;56:123-136.

31 Manne S, Badr H: Intimacy and relationship processes in couples' psychosocial adaptation to cancer. Cancer Suppl 2008;112:2541-2555.

32 Manne S, Ostroff J, Rini C, Fox K, Goldstein L, Grana G: The interpersonal process model of intimacy: the role of self-disclosure, partner disclosure, and partner responsiveness in interactions between breast cancer patients and their partners. J Fam Psychol 2004;18:589-599.

33 Manne SL, Ostroff JS, Norton TR, Fox K, Goldstein L, Grana G: Cancer-related relationship communication in couples coping with early stage breast cancer. Psychooncology 2006;15:234-247.

34 Badr H, Taylor CL: Effects of relationship maintenance on psychological distress and dyadic adjustment among couples coping with lung cancer. Health Psychol 2008;27:616-627.

35 Northouse LL, Katapodi MC, Song L, Zhang L, Mood DW: Interventions with family caregivers of cancer patients: meta-analysis of randomized trials. CA Cancer J Clin 2010;60:317-339. 
36 Martire LM, Schulz R, Helgeson VS, Small BJ, Saghafi EM: Review and meta-analysis of couple-oriented interventions for chronic illness. Ann Behav Med 2010; 40:325-342.

37 Regan TW, Lambert S, Girgis A, Kelly B, Kayser K, Turner J: Do couple-based interventions make a difference for couples affected by cancer? A systematic review. BMC Cancer 2012;12:279.

38 Faller H, Schuler M, Richard M, Heckl U, Weis J, Kuffner R: Effects of psycho-oncologic interventions on emotional distress and quality of life in adult patients with cancer: systematic review and meta-analysis. J Clin Oncol 2013;31:782-793.

39 Baik OM, Adams KB: Improving the well-being of couples facing cancer: a review of couples-based psychosocial interventions. J Marital Fam Ther 2011;37 250-266.
Fredman SJ, Baucom DH, Gremore TM, Castellani AM, Kallman TA, Porter LS, Kirby JS, Dees EC, Klauber-Demore N, Peppercorn J, Carey LA: Quantifying the recruitment challenges with couple-based interventions for cancer: applications to early-stage breast cancer. Psychooncology 2009;18:667-673.

41 Linden W, Satin JR: Avoidable pitfalls in behavioral medicine outcome research. Ann Behav Med 2007;33: 143-147.

42 Baucom DH, Kirby JS, Kelly JT: Couple-based interventions to assist partners with psychological and medical problems; in Hahlweg K, Grawe-Gerber M, Baucom DH (eds): Enhancing Couples: The Shape of Couple Therapy to Come. Göttingen, Hogrefe, 2009, pp 79-93.

43 Henselmans I, Sanderman R, Baas PC, Smink A, Ranchor AV: Personal control after a breast cancer diagnosis: stability and adaptive value. Psychooncology 2009; 18:104-108.
44 Kim Y, Kashy DA, Spillers RL, Evans TV: Needs assessment of family caregivers of cancer survivors: three cohorts comparison. Psychooncology 2010;19:573-582.

45 Kalaitzi C, Papadopoulos VP, Michas K, Vlasis K, Skandalakis P, Filippou D: Combined brief psychosexual intervention after mastectomy: effects on sexuality, body image, and psychological well-being. J Surg Oncol 2007;96:235-240

46 Zimmermann T, Heinrichs N: Auswirkungen einer psychoonkologischen Intervention für Paare auf die Sexualität bei einer Brustkrebserkrankung der Frau. Z Gesundheitspsychol 2011;19:23-34.

47 Scott JL, Halford WK, Ward B: United we stand? The effects of a couple-coping intervention on adjustment to breast or gynaecological cancer. J Consult Clin Psychol 2004;72:1122-1135. 